\title{
PENGEMBANGAN SISTEM INFORMASI SMS GATEWAY DALAM MENINGKATAN LAYANAN PADA STMIK MAHAKARYA
}

\author{
Ahmad Jurnaidi Wahidin \\ Teknologi Informasi, Universitas Bina Sarana Informatika \\ J1. Kramat Raya No.98, RT.2/RW.9, Kwitang, Kec. Senen, Kota Jakarta Pusat, DKI Jakarta, 10450 \\ E-mail : ahmad.ajn@bsi.ac.id
}

\begin{abstract}
ABSTRAK
Kebutuhan mendapatkan informasi secara cepat dan akurat menuntut semua aspek untuk melakukan pengembangan dalam bidang teknologi informasi agar dapat bersaing. Kampus STMIK Mahakarya yang merupakan salah satu pendukung perkembangan kehidupan dalam aspek pendidikan harus berkembang agar bertahan dan bersaing dengan perguruan tinggi lainnya. Salah satu teknologi yang berkembang pesat adalah teknologi seluler dan salah satu fitur yang mudah digunakan adalah text messaging atau yang sering kita sebut dengan SMS (Short Message Service). Mudahnya penggunaan SMS dan biaya yang murah menjadikan siapa saja dapat menggunakannya. Hal tersebut menjadi latar belakang penulis untuk melakukan pengemban sistem yang berbasis SMS Gateway di kampus STMIK Mahakarya guna meningkatkan layanan akademik. Pembuatan sistem SMS Gateway berbasis web ini dibangun untuk memberikan informasi mahasiswa dan calon mahasiswa. Pada sistem sebelumnya di kampus STMIK Mahakarya layanan pemberian informasi masih menggunakan sistem manual yaitu tatap muk, sehingga dengan adanya sistem yang dibangun dapat mempermudah penyampaian informasi kepada mahasiswa dan calon mahasiswa. Pengujian terhadap sistem dilakukan menggunakan pengujian black box dengan hasil semua diterima dan dilakukan juga user acceptance test menggunakan skala likert untuk mengetahui penilaian sistem dari user secara langsung, dari hasil pengujian didapat nilai persentase adalah $89 \%$ dimana angka tersebut terdapat pada interval dengan pernyataan sangat setuju.
\end{abstract}

Kata Kunci: Sistem Informasi, SMS (Short Message Service), SMS Gateway, Web, Informasi

\section{PENDAHULUAN}

Kebutuhan mendapatkan informasi secara cepat, tepat dan akurat dari berbagai sumber mendorong manusia untuk selalu meningkatkan melalui teknologi, saat ini sudah umum setiap manusia menggunakan telepon seluler atau hand phone, dimana setiap manusia dapat melakukan komunikasi secara mudah dan dapat dibawa kemana-mana.

Badan Pusat Statistik (BPS) mencatat, pelanggan telepon seluler di Indonesia sebanyak 131,66 per 100 penduduk pada 2020. Jumlah itu meningkat 2,3\% dibandingkan pada tahun sebelumnya yang sebesar 128,7 per 100 penduduk (Dhini, 2021). Data itu menunjukkan bahwa ada 131,66 pelanggan telepon seluler pada setiap 100 penduduk Indonesia. Dengan demikian, satu penduduk Indonesia bisa berlangganan lebih dari satu kartu subscriber identity module (SIM).

Banyak fasilitas yang dapat digunakan dari hand phone, salah satunya adalah SMS (Short Message Sistem). SMS adalah salah satu fitur layanan sistem telekomunikasi bergerak yang mampu mentransmisikan pesan singkat berupa alphanumeric antar telepon seluler atau ke perangkat lainnya (Pineng, 2017). Mudahnya penggunaan aplikasi SMS dan biaya yang murah, jadi siapa saja dapat menggunakan atau memanfaatkan aplikasi ini. Sehingga SMS merupakan salah satu alternatif sebagai alat komunikasi yang dapat diimplementasikan di berbagai kebutuhan.

Mobile advertising berkembang diantaranya melalui SMS Gateway Server sehingga pesan promosi melalui iklan dapat disebarkan secara luas, secara cepat sehingga pesan dapat segera diterima oleh pelanggan atau bisa disebut dengan istilah SMS Blast (Briandana, Lestari and Marta, 2020)

STMIK Mahakarya merupakan sebuah perguruan tinggi dengan kelompok kampus berkembang, dimana banyak hal yang masih dalam proses perbaikan atau pengembangan untuk dapat bersaing dengan perguruan tinggi lainnya. Masih kurangnya sarana komunikasi dalam penyampaian informasi dari lembaga kampus kepada mahasiswa STMIK Mahakarya merupakan salah satu masalah penghambat dari perkembangan kampus, sehingga menuntut perlu adanya pengembangan sistem di dalamnya. Sudah ada metode penyampaian informasi akademik sebelumnya yaitu melalui tatap muka secara langsung dengan bagian akademik dan datang langsung ke marketing kampus untuk mengetahui perihal pendaftaran calon mahasiswa. Namun masih belum efektif dikarenakan informasi memerlukan waktu yang lumayan lama. Perlu sebuah teknologi yang dapat membantu proses penyampaian informasi akademik kepada mahasiswa dan informasi pendaftaran terhadap calon mahasiswa STMIK Mahakarya. 
Sekarang ini SMS dapat kita manfaatkan untuk berbagai aplikasi, contohnya adalah Pooling interaktif, Mobile Banking, Marketing dan lainnya. Karena begitu mudahnya cara penggunaan aplikasi SMS ini sehingga sangat tepat bila teknologi ini diaplikasikan dalam proses pengembangan kampus STMIK Mahakarya.

SMS Gateway adalah suatu platform yang menyediakan mekanisme untuk menghantarkan dan menerima SMS dari peralatan mobile (HP, PDA, Phone, dll) melalui SMS Gateway short code (Shodikun and Syam, 2018). Pesan-pesan SMS dikirim dari sebuah telepon genggam ke pusat pesan yaitu Short Message Service Centre (SMSC), di sini pesan disimpan dan dikirim selama beberapa kali. Pada penelitian ini menggunakan aplikasi bantuan yaitu gammu, gammu yang merupakan sebuah aplikasi yang digunakan untuk mengelola berbagai fungsi pada hand phone, modem dan perangkat sejenisnya (Masruri and Creativity, 2015).

Pada penelitian yang dilakukan di SMK Telkom Bandung SMS Gateway dapat menyampaikan informasi laporan absensi dan nilai akhir siswa kepada orang tua dengan cepat, Guru dapat menyajikan dan mengevaluasi laporan absensi dan nilai dengan status yang lebih rapi, lengkap dan detail, serta orang tua dapat menerima notifikasi (Utari and Triana, 2019) .

Sistem informasi pembayaran SPP berbasis desktop dan SMS Gateway yang dibangun di SMK Negeri 1 Bandar Lampung bertujuan untuk membantu dalam pengolahan transaksi pembayaran SPP di. Hasil pengujian setelah dibangun sistem yang baru menggunakan aplikasi desktop dan SMS Gateway dan dilakukan pengujian didapatkan hasil (95\%) sehingga kualitas pembayaran SPP pada SMK Negeri 1 Bandar Lampung meningkat $65 \%$ (Tantowi, Pasha and Priandika, 2021).

Berdasarkan latar belakang tersebut, maka penulis melakukan pengembangan dengan memanfaatkan SMS Gateway melalui web dengan bahasa pemrograman PHP untuk mengirim pesan kepada mahasiswa STMIK Mahakarya dan calon mahasiswa agar dapat dengan cepat dalam memperoleh informasi yang diberikan oleh pihak kampus.

\section{RUANG LINGKUP}

Ruang lingkup pada penelitian ini adalah pembuatan sistem SMS Gateway di Kampus STMIK Mahakarya, berbasis web, pembuatan sistem SMS Gateway ini menggunakan bahasa pemrograman PHP dan menggunakan modem Huawei E353 HSPA + USB Stick dan menggunakan database bantu yaitu Gammu

Pengiriman SMS hanya dapat dikirimkan kepada mahasiswa yang datanya sudah dimasukan kedalam database sistem, dan untuk calon mahasiswa pesan atau SMS Autoreply hanya dikirim jika format yang dikirim benar.

Perumusan masalah pada penelitian ini apakah sistem SMS Gateway yang dibuat dapat berfungsi dan dapat mengirimkan pesan ke nomor mahasiswa yang sudah ada di dalam basis data serta sistem dapat menerima pesan yang dikirimkan.

\section{BAHAN DAN METODE}

Pada bagian ini memaparkan bahan serta metode yang digunakan pada penelitian ini, dan juga metode pengujian sistem yang dibangun menggunakan metode black box dan metode user acceptance test sebagai pengujian user terhadap sistem yang dibangun.

\subsection{Kebutuhan Perangkat}

Komputer terdiri dari perangkat keras dan perangkat lunak yang saling berinteraksi, dimana perangkat lunak memberikan instruksi kepada perangkat keras untuk melakukan tugas tertentu, sehingga dapat menjalankan suatu sistem di dalamnya.

Pada sistem SMS Gateway ini, perangkat keras yang digunakan adalah:

1. Komputer/Laptop

2. Modem

3. Hand phone

4. SIM Card

5. Port USB

Sedangkan untuk perangkat lunak digunakan dalam sebuah sistem merupakan perintah-perintah yang diberikan kepada perangkat keras agar bisa saling berinteraksi di antara keduanya. Perangkat lunak yang dibutuhkan dalam membangun sistem SMS Gateway untuk STMIK Mahakarya ini adalah:

1. Sistem operasi windows 7

2. Aplikasi web browser

3. Appserv

4. Gammu

5. Macromedia Dreamweaver

\subsection{Metode Pengembangan Sistem}

Metode penelitian yang digunakan untuk pengembangan adalah pendekatan dengan menggunakan Waterfall Process Model. Waterfall Process Model adalah dimana pengerjaan sistem ini dilakukan secara berurutan dalam beberapa level dan tidak akan berlanjut ke level selanjutnya apabila level sebelumnya tidak di selesaikan terlebih dahulu.

Metode waterfall diimplementasikan dalam membangun aplikasi supaya aplikasi yang dihasilkan lebih baik dan berkualitas (Dini and Agmawarnida, 2018). Dengan pendekatan ini diharapkan semua kebutuhan sistem dapat didefinisikan secara utuh, eksplisit, dan benar

Adapun tahapan dalam pengembangan sistem ini meliputi:

1. Perencanaan (Planning)

Tahap perencanaan adalah tahap awal yang dilakukan penulis, mencari latarbelakang dan menentukan penyelesaian nya. Perencanaan berawal dari penentuan tempat penelitian, menganalisa masalah secara umum dan menentukan cara penyelesaiannya.

2. Analisis Sistem (Sistem Analysis) 
Tahap ini merupakan tahap dimana menganalisa kebutuhan sistem yang sedang berjalan yang akan digunakan untuk acuan dalam pembuatan program. Dalam tahapan ini pengumpulan data didapatkan dari berbagai cara, yaitu: Studi pustaka, observasi dan wawancara.

3. Pembuatan Sistem (Sistem Development)

Pembuatan sistem merupakan tahap dimana penulis akan membuat sebuah program menggunakan bahasa pemrograman PHP, dengan bahasa pemrograman ini maka desain sistem yang telah dirancang akan diterapkan menjadi aplikasi yang berbasis web. Pembuatan sistem berdasarkan hasil analisis sebelumnya, sehingga sistem dibuat berdasarkan kebutuhan yang ada.
4. Implementasi Sistem (Sistem Implementation) Tahap ini penulis mencoba menguji sistem dan menerapkan kepada mahasiswa STMIK Mahakarya.

\subsection{Perancangan Sistem}

Pada tahap perancangan sistem bertujuan mengimplementasikan kebutuhan-kebutuhan sistem yang diusulkan berdasarkan hasil Analisis sistem berjalan. Menurut (Sabharwal, Kaur and Sibal, 2017) Use Case Diagram adalah gambaran yang dibuat selama awal fase pengembangan perangkat lunak yang signifikan untuk merumuskan, menguatkan dan mendokumentasikan perilaku sistem. Pada penelitian ini use case diagram yang diusulkan ditampilkan pada gambar 1 .

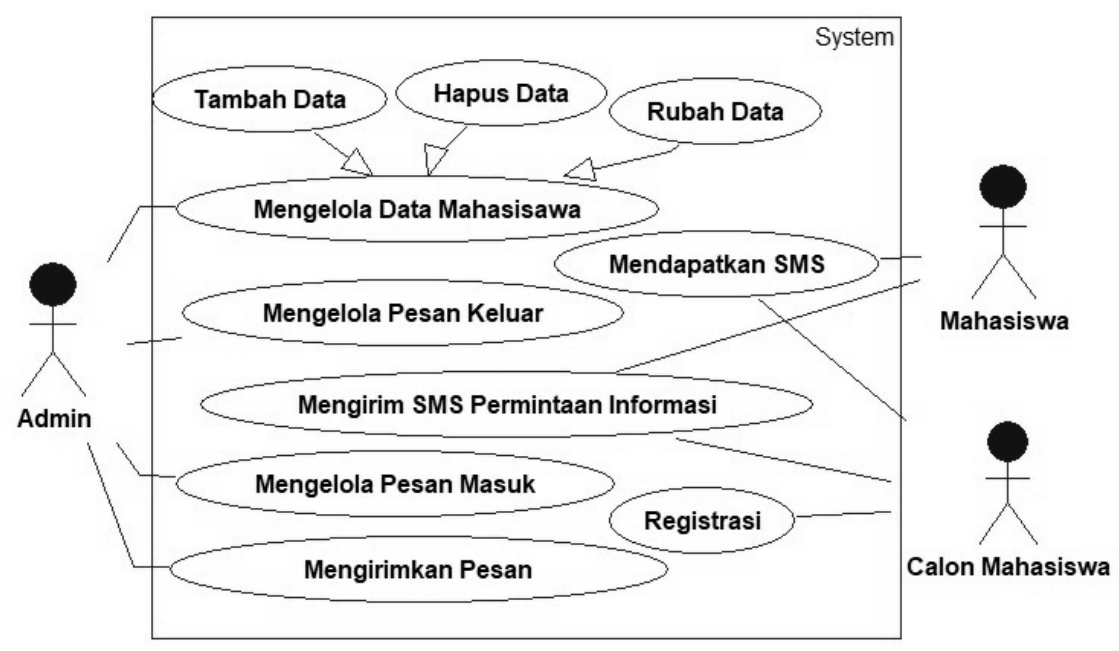

Gambar 1. Use Case Diagram

Pada gambar 1 menjelaskan interaksi antara aktor dengan sistem, dimana pada use case diagram yang ditampilkan pada gambar 1 menunjukkan terdapat tiga aktor yang dapat berinteraksi dengan sistem, aktor admin dapat melakukan aktivitas kedalam sistem sebanyak 5 use case, untuk mahasiswa berinteraksi dengan 2 use case sedangkan untuk calon mahasiswa berinteraksi dengan 3 use case. Identifikasi ketiga aktor dijelaskan pada tabel 1 .

Tabel 1. Identifikasi Aktor

\begin{tabular}{|l|l|l|}
\hline No & \multicolumn{1}{|c|}{ Aktor } & \multicolumn{1}{c|}{ Deskripsi } \\
\hline 1 & Admin & $\begin{array}{l}\text { Merupakan aktor yang berperan } \\
\text { dalam mengelola sistem SMS } \\
\text { Gateway melalui web. }\end{array}$ \\
\hline 2 & Mahasiswa & $\begin{array}{l}\text { Merupakan aktor yang berperan } \\
\text { dalam menggunakan sistem informasi } \\
\text { akademik melalui hand phone. }\end{array}$ \\
\hline 3 & $\begin{array}{l}\text { Calon } \\
\text { Mahasiswa }\end{array}$ & $\begin{array}{l}\text { Merupakan aktor yang berperan } \\
\text { dalam menggunakan sistem informasi } \\
\text { akademik melalui hand phone. }\end{array}$ \\
\hline
\end{tabular}

Tabel 1 yang menjelaskan identifikasi aktor dimana aktor yang berperan dalam menjalankan sistem SMS Gateway di STMIK Mahakarya, aktor admin adalah staff kampus yang diberi akses untuk menjalankan sistem yang dibuat melalui web. Sedangkan untuk mahasiswa dan calon mahasiswa memanfaatkan sistem yang dibuat hanya melalui hand phone dengan mengirim atau menerima pesan. 
Kemudian untuk merancang database penelitian ini menggunakan Entity Relationship Diagram (ERD). Entity Relationship Diagram atau ERD adalah sebuah diagram struktural yang digunakan untuk merancang sebuah Database (Latukolan, Arwan and Ananta, 2019). Dalam pembuatan basis data terlebih dahulu harus menentukan beberapa komponen dan relasi yang diperlukan untuk menyusun dan menyimpan informasi dalam perangkat komputer dengan benar. Dan Entity Relationship Diagram (ERD) merupakan langkah awal dalam menyusun sebuah basisdata. Entity Relationship Diagram (ERD) dibuat agar lebih mudah dalam menggambarkan data yang memiliki hubungan atau relasi dalam bentuk sebuah desain. Dengan dibuatnya ERD maka sistem basisdata yang akan dibangun dapat digambarkan lebih detail, lebih terstruktur dan terlihat rapi. Entity Relationship Diagram (ERD) pada penelitian ini ditampilkan pada gambar 2 .

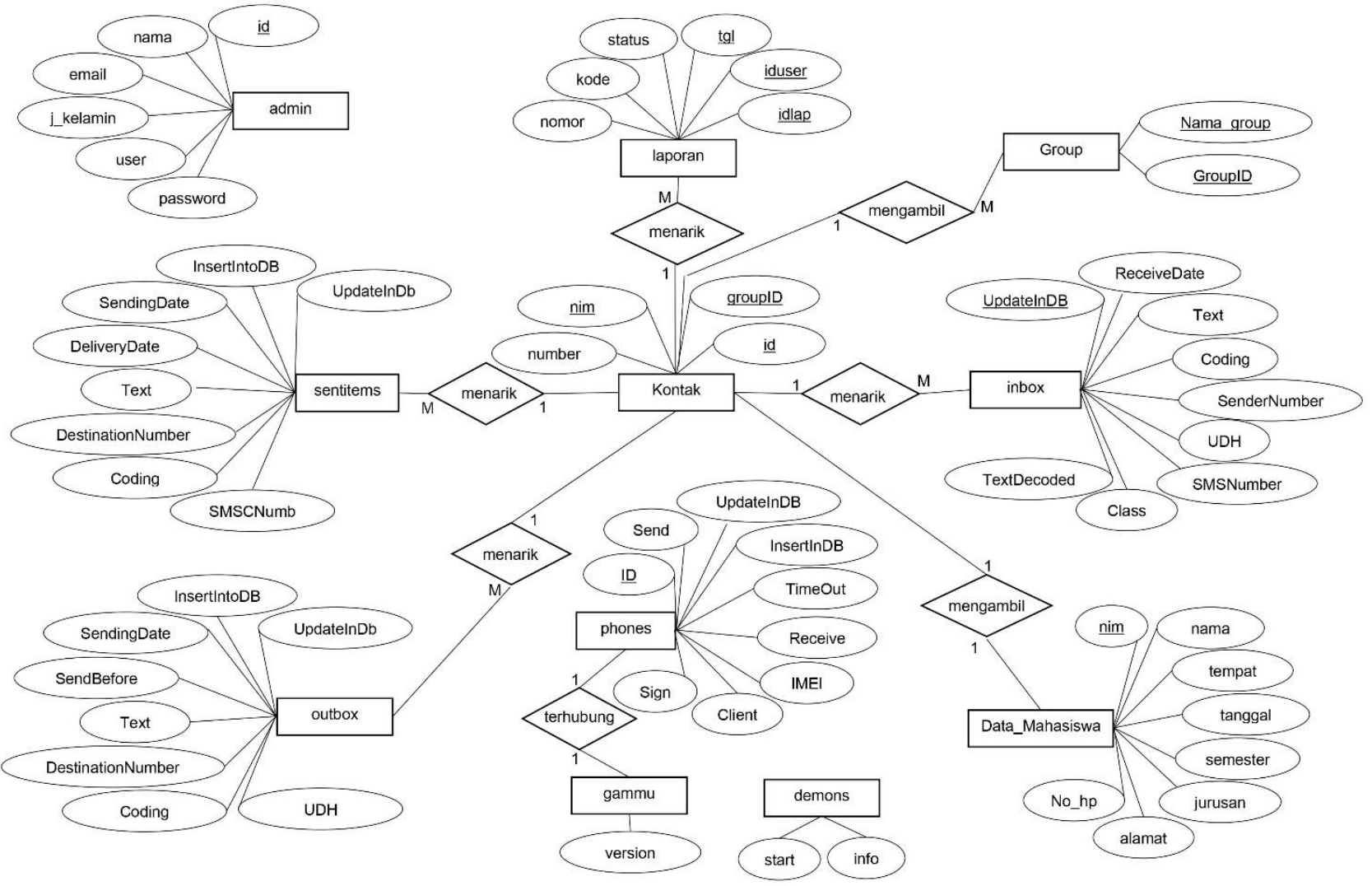

Gambar 2. Rancangan Entity Relationship Diagram

Dengan adanya ERD, maka sistem database yang akan dibuat dapat digambarkan dengan lebih terstruktur. Pada gambar 2 menjelaskan terdapat 11 entitas dengan setiap entitas memiliki atributnya masing-masing. Contoh pada entitas data mahasiswa memiliki atribut nim, nama, tempat, tanggal, semester, jurusan dan alamat.

Class Diagram merupakan gambaran hubungan antar kelas atau tabel yang digunakan dalam sistem (Suendri, 2019).
Class sebagai objek dan memiliki atribut dan perilaku atau operasi, pada gambar 7 menjelaskan 11 kelas atau objek dengan atribut yang melekat pada setiap objeknya, dan nilai dari suatu kelas hanya dapat diproses dari objek yang dimiliki saja. Selain atribut setiap kelas juga memiliki operasinya masing-masing, dimana proses yang dapat dilakukan oleh sebuah kelas baik pada kelas sendiri ataupun kepada kelas lainnya. Class diagram pada penelitian ini dapat dilihat dari gambar 3 . 

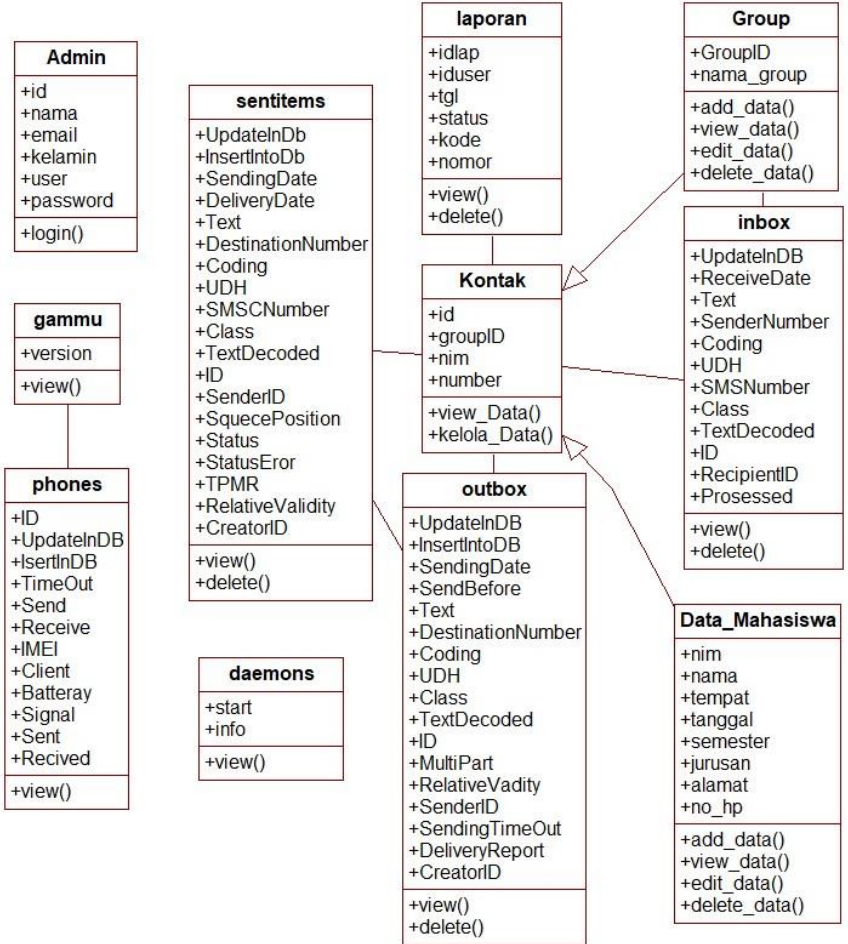

Gambar 3. Rancangan Class Diagram

Dan untuk rancangan basis data untuk admin dijelaskan pada tabel 2.

Tabel 2. Rancangan Basis Data Admin

\begin{tabular}{|l|l|l|}
\hline Nama field & Tipe Data & Keterangan \\
\hline Id & int(3) & Id dari setiap admin \\
\hline Nama & varchar(30) & Nama dari admin \\
\hline Email & varchar(50) & Email admin \\
\hline Kelamin & varchar(8) & Jenis kelamin dari admin \\
\hline User & varchar(30) & User untuk login dari admin \\
\hline Password & varchar(30) & $\begin{array}{l}\text { Password yang } \\
\text { menggunakan MD5 }\end{array}$ \\
\hline
\end{tabular}

Dari diagram dan basis data yang sudah dibahas, terbentuklah rancangan antarmuka struktur menu yang ditampilkan pada gambar 4 .

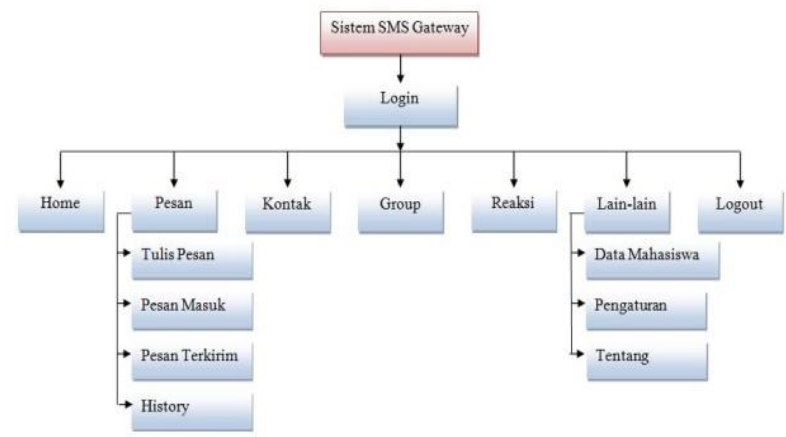

Gambar 4. Rancangan Antarmuka Struktur Menu
Terdapat tujuh menu utama pada rancangan antarmuka, dan beberapa menu utama memiliki sub menunya, dan setiap menu dijelaskan pada tabel 3 .

Tabel 3. Deskripsi Menu

\begin{tabular}{|c|c|}
\hline Menu & Deskripsi \\
\hline Login & $\begin{array}{l}\text { Menu paling awal yang wajib dipilih oleh } \\
\text { admin }\end{array}$ \\
\hline Home & Menu yang menunjukkan tampilan utama \\
\hline Pesan & Menu untuk mengolah pesan \\
\hline Tulis Pesan & Sub menu untuk mengirimkan pesan \\
\hline Pesan Masuk & Sub menu untuk melihat pesan masuk \\
\hline Pesan Terkirim & Sub menu untuk melihat pesan yang dikirim \\
\hline History & Sub menu untuk melihat semua pesan \\
\hline Kontak & Menu yang berisi daftar kontak \\
\hline Group & Menu yang berisi daftar group \\
\hline Reaksi & Menu untuk mengelola pesan Autoreply \\
\hline Lain-lain & Menu yang berisi sub menu tambahan \\
\hline $\begin{array}{l}\text { Data } \\
\text { Mahasiswa }\end{array}$ & Sub menu untuk mengelola data mahasiswa \\
\hline Pengaturan & Sub menu untuk mengatur sistem \\
\hline Tentang & $\begin{array}{l}\text { Sub menu yang berisi tentang sistem SMS } \\
\text { Gateway }\end{array}$ \\
\hline Logout & Menu untuk keluar dari sistem \\
\hline
\end{tabular}

Penelitian ini juga merancang arsitektur jaringan untuk mendukung perancangan sistem SMS Gateway di kampus STMIK Mahakarya yang ditampilkan pada gambar 5 . 


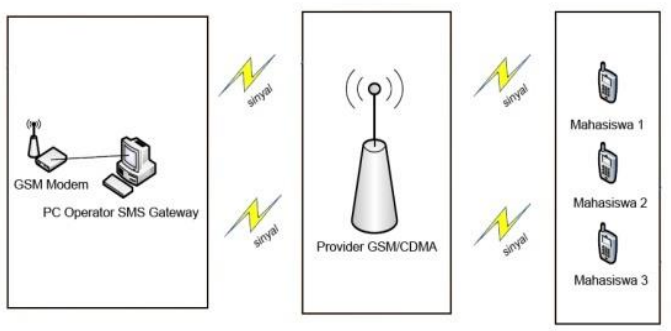

Gambar 5. Rancangan Arsitektur Jaringan

\subsection{Metode Pengujian Sistem}

Pada pengujian penulis menggunakan metode black box, pengujian kotak hitam mempertimbangkan nilainya masukan pada studi (Supriyono, 2020). Black-box testing ini lebih menguji ke tampilan luar (Interface) dari suatu aplikasi agar mudah digunakan oleh pengguna. Dan penerapannya penulis mencoba memasukan data dari mahasiswa dan mengirimkan pesan ke nomor yang dicantumkan.

\subsection{Metode Pengujian User Acceptance Test (UAT)}

Pengujian user acceptance test adalah pengujian yang dilakukan end-user dimana user berinteraksi langsung dengan sistem (Supriatna, 2019). Pada penelitian ini penulis melibatkan admin kampus dan mahasiswa untuk memberikan penilaian melalui kuesioner, kemudian hasil kuesioner akan dilakukan perhitungan untuk mendapatkan kesimpulan terhadap penilaian sistem yang dibuat. Pengujian ini dilakukan menggunakan skala likert dengan skala 1 sampai 5, dan hasil skala akan dihitung persentasenya menggunakan persamaan (1).

$$
\text { Index } \%=\frac{\text { Total Skor }}{\mathrm{Y}} \times 100
$$

Dimana (1)

$\mathrm{Y}=$ Skor tertinggi likert $\mathrm{x}$ Jumlah jawaban

Dalam menghitung persentase perlu diketahui terlebih dahulu total skor, untuk mencari total skor dapat menggunakan persamaan (2).

Dimana (2)

$$
\text { Total Skor }=\sum \mathrm{TxPn}
$$

$\mathrm{T}=$ Total Jumlah Jawaban

Pn=Pilihan Angka Skor Likert

Dari hasil perhitungan akan mendapatkan persentase yang kemudian dimasukan kedalam interval dan di konversi menjadi kesimpulan, dan untuk menghitung interval pada skala likert dapat dihitung menggunakan persamaan (3).

Dimana (3)

$$
I=\frac{100}{\text { Jumlah Skor Likert }}
$$

\section{PEMBAHASAN}

Pada bagian ini membahas implementasi sistem sampai sistem diuji menggunakan pengujian black box dan pengujian user acceptance test.

\subsection{Implementasi Sistem}

Implementasi sistem merupakan tahapan yang menjelaskan bagaimana sistem yang telah dibuat, sistem SMS Gateway ini dapat dijalankan pada komputer dengan bantuan modem GSM.

Sebelum masuk ke layar utama setiap user harus melakukan login, form login ditampilkan pada gambar 6 .

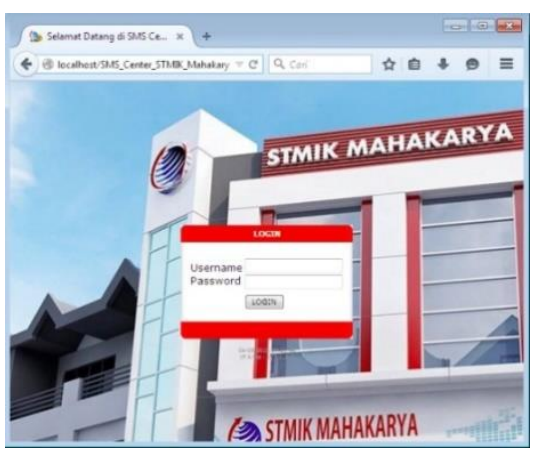

Gambar 6. Form Login

Pada form login diminta memasukan username dan password, jika berhasil maka akan masuk ke halaman utama, tampilan halaman utama terdapat pada gambar 7 .

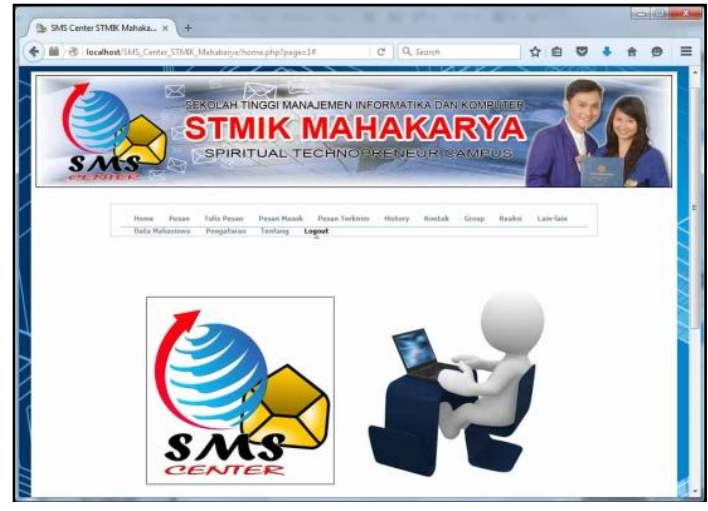

Gambar 7. Tampilan Halaman Utama

Pada halaman utama menampilkan menu-menu yang dapat dipilih, salah satu menu adalah pesan masuk yang tampilan layarnya dapat dilihat pada gambar 8 .

I= Interval 


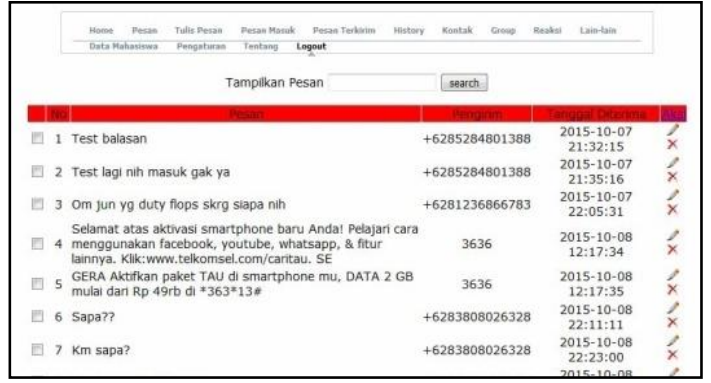

Gambar 8. Tampilan Pesan Masuk

Pada layar pesan masuk menampilkan isi pesan, nomor pengirim dan tanggal pesan diterima serta aksi yang dapat dilakukan oleh admin. Selain pesan masuk admin juga bisa memilih menu pesan keluar, tampilan layan pesan keluar pada gambar 9 .

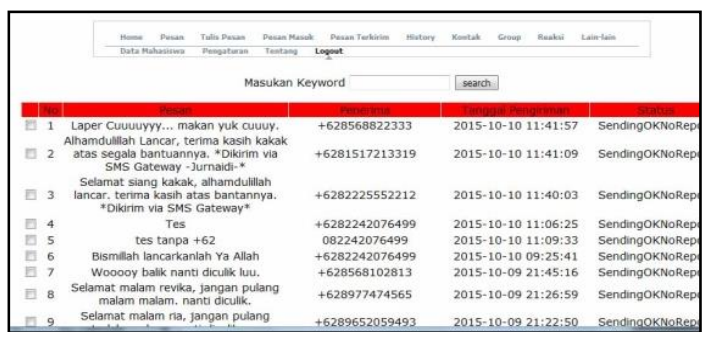

Gambar 9. Tampilan Pesan Keluar

Pesan keluar menampilkan pesan yang dikirim, nomor dari penerima pesan, tanggal pengiriman serta status dari pesan. Jika pesan terkirim maka akan menampilkan status Sending $O K$.

Admin juga dapat mengelola data mahasiswa secara manual, dapat dilakukan penambahan data dan perubahan data pada form Kelola data mahasiswa sesuai gambar 10.

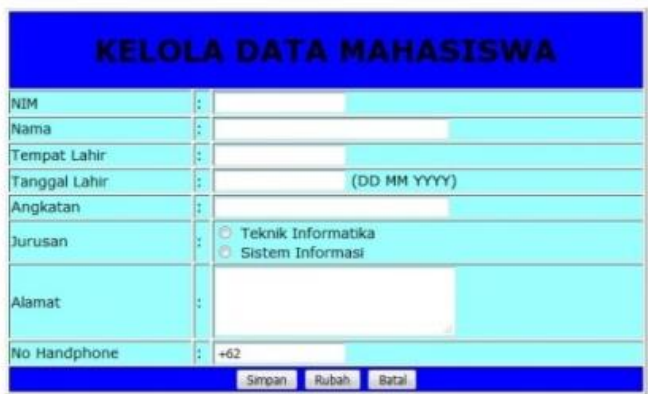

Gambar 10. Form Kelola Data Mahasiswa

Pada menu kontak menampilkan list nama dan nomor hand phone dari mahasiswa dan group sebagaimana ditampilkan pada gambar 11.

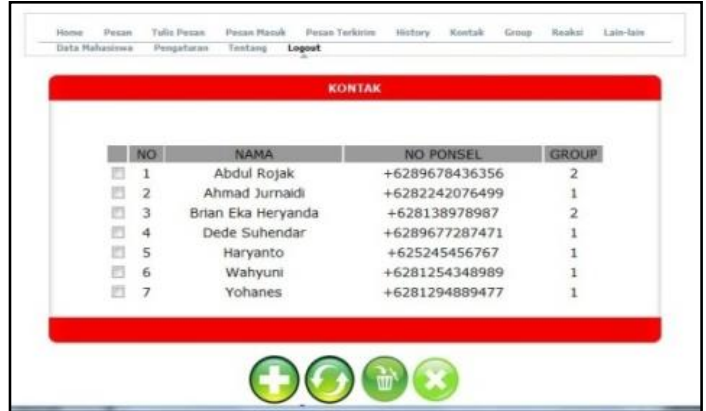

Gambar 11. Tampilan Kontak

Selain tampilan kontak juga terdapat menu group yang ditampilkan pada gambar 12 .

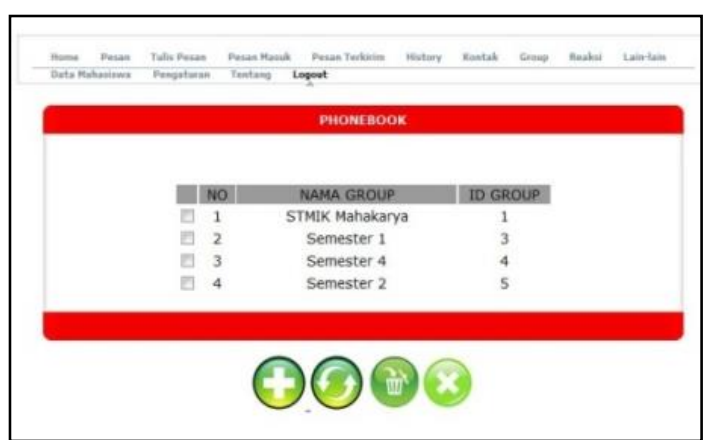

Gambar 12. Tampilan Group

Pada gambar 12 menampilkan tampilan group dengan nama dan id group.

\subsection{Pengujian Black Box}

Pengujian pada penelitian ini menggunakan pengujian black box, dimana pengujian diperlukan untuk mengetahui apakah sistem yang dibuat dapat berfungsi dengan baik. Pengujian dilakukan dengan mencoba fungsi modem dan menu yang terdapat pada sistem. Pengujian dapat dilihat pada tabel 4.

Tabel 4. Pengujian Black Box

\begin{tabular}{|c|c|c|c|}
\hline $\begin{array}{l}\text { Aktivitas } \\
\text { Pengujian }\end{array}$ & $\begin{array}{l}\text { Hasil yang } \\
\text { diharapkan }\end{array}$ & $\begin{array}{c}\text { Hasil } \\
\text { pengujian }\end{array}$ & Ket. \\
\hline $\begin{array}{l}\text { Koneksi } \\
\text { Modem }\end{array}$ & $\begin{array}{ll}\text { Sistem } & \text { ter } \\
\text { koneksi } & \\
\text { dengan } & \\
\text { modem } & \end{array}$ & $\begin{array}{l}\text { Sistem } \\
\text { berhasil ter } \\
\text { koneksi } \\
\text { dengan } \\
\text { modem }\end{array}$ & $\begin{array}{l}\text { [x]Diterima } \\
{[\text { ]Ditolak }}\end{array}$ \\
\hline Form Login & $\begin{array}{l}\text { Dengan user } \\
\text { dan password } \\
\text { yang benar } \\
\text { login berhasil; }\end{array}$ & $\begin{array}{l}\text { Masuk ke } \\
\text { halaman } \\
\text { utama }\end{array}$ & $\begin{array}{l}\text { [x]Diterima } \\
{[\text { ]Ditolak }}\end{array}$ \\
\hline $\begin{array}{l}\text { Menu } \\
\text { Pesan } \\
\text { Masuk }\end{array}$ & $\begin{array}{l}\text { Menampilkan } \\
\text { layar pesan } \\
\text { masuk }\end{array}$ & $\begin{array}{l}\text { Tampil } \\
\text { layar pesan } \\
\text { masuk }\end{array}$ & $\begin{array}{l}\text { [x]Diterima } \\
{[\text { ]Ditolak }}\end{array}$ \\
\hline $\begin{array}{l}\text { Menu > } \\
\text { Pesan } \\
\text { Keluar }\end{array}$ & $\begin{array}{l}\text { Menampilkan } \\
\text { layar pesan } \\
\text { keluar }\end{array}$ & $\begin{array}{l}\text { Tampil } \\
\text { layar pesan } \\
\text { keluar }\end{array}$ & $\begin{array}{l}\text { [x]Diterima } \\
{[\text { ]Ditolak }}\end{array}$ \\
\hline $\begin{array}{l}\text { Kelola Data } \\
\text { Mahasiswa }\end{array}$ & $\begin{array}{l}\text { Menambah } \\
\text { data }\end{array}$ & $\begin{array}{l}\text { Data } \\
\text { tersimpan }\end{array}$ & $\begin{array}{l}\text { [x]Diterima } \\
\text { [ ]Ditolak }\end{array}$ \\
\hline
\end{tabular}




\begin{tabular}{|c|c|c|c|}
\hline & mahasiswa & & \\
\hline $\begin{array}{l}\text { Menu } \\
\text { Kontak }\end{array}$ & $\begin{array}{l}\text { Menampilkan } \\
\text { layar kontak }\end{array}$ & $\begin{array}{l}\text { Tampil } \\
\text { layar } \\
\text { kontak }\end{array}$ & $\begin{array}{l}\text { [x]Diterima } \\
\text { [ ]Ditolak }\end{array}$ \\
\hline $\begin{array}{l}\text { Menu } \\
\text { Group }\end{array}$ & $\begin{array}{l}\text { Menampilkan } \\
\text { layar group }\end{array}$ & $\begin{array}{l}\text { Tampil } \\
\text { layar group }\end{array}$ & $\begin{array}{l}\text { [x]Diterima } \\
\text { [ ]Ditolak }\end{array}$ \\
\hline $\begin{array}{l}\text { Mengirim } \\
\text { sms }\end{array}$ & $\begin{array}{l}\text { Pesan terkirim } \\
\text { dan diterima }\end{array}$ & $\begin{array}{l}\text { Pesan } \\
\text { masuk di } \\
\text { hand phone } \\
\text { penerima }\end{array}$ & $\begin{array}{l}\text { [x]Diterima } \\
\text { [ ]Ditolak }\end{array}$ \\
\hline
\end{tabular}

Dari hasil pengujian dapat semua proses pengujian sesuai dengan yang diharapkan, selain pengujian sistem melalui pengujian black box, penulis juga melakukan pengujian terhadap user dengan pengujian user acceptance test.

Pengujian user acceptance test adalah pengujian yang melibatkan user untuk langsung menggunakan sistem yang sudah dibangun dan memberi penilaian, penilaian dilakukan oleh user melalui media kuesioner yang diberikan penulis. Pengujian dilakukan secara objektif dimana diuji secara langsung ke admin dan mahasiswa. Kuesioner dilakukan perhitungan untuk dapat diambil kesimpulan terhadap penilaian sistem dengan menggunakan skala likert dengan skala 1 sampai 5, dengan ketentuan sesuai ditunjukkan pada tabel 5 .

\section{Table 5 Skala Likert}

\begin{tabular}{|l|c|}
\hline \multicolumn{1}{|c|}{ Skala } & Bobot \\
\hline Tidak Setuju & 1 \\
\hline Kurang Setuju & 2 \\
\hline Cukup Setuju & 3 \\
\hline Setuju & 4 \\
\hline Sangat Setuju & 5 \\
\hline
\end{tabular}

Pengujian dilakukan terhadap 10 orang dengan jumlah 10 pertanyaan dan dengan hasil yang ditunjukkan pada tabel 6 .

Tabel 6 Hasil Perhitungan Kuesioner

\begin{tabular}{|c|c|c|c|c|c|c|c|c|c|c|c|}
\hline Responden & SS & $\mathrm{S}$ & $\mathrm{CS}$ & TS & STS & Total & SS $\%$ & $\mathrm{~S} \%$ & CS\% & KS\% & T S\% \\
\hline 1 & 4 & 5 & 1 & 0 & 0 & 10 & \multirow{11}{*}{$50 \%$} & \multirow{11}{*}{$44 \%$} & \multirow{11}{*}{$6 \%$} & \multirow{11}{*}{$0 \%$} & \multirow{11}{*}{$0 \%$} \\
\hline 2 & 5 & 5 & 0 & 0 & 0 & 10 & & & & & \\
\hline 3 & 6 & 3 & 1 & 0 & 0 & 10 & & & & & \\
\hline 4 & 4 & 5 & 1 & 0 & 0 & 10 & & & & & \\
\hline 5 & 5 & 5 & 0 & 0 & 0 & 10 & & & & & \\
\hline 6 & 6 & 4 & 0 & 0 & 0 & 10 & & & & & \\
\hline 7 & 5 & 4 & 1 & 0 & 0 & 10 & & & & & \\
\hline 8 & 6 & 4 & 0 & 0 & 0 & 10 & & & & & \\
\hline 9 & 4 & 5 & 1 & 0 & 0 & 10 & & & & & \\
\hline 10 & 5 & 4 & 1 & 0 & 0 & 10 & & & & & \\
\hline Jumlah & 50 & 44 & 6 & 0 & 0 & 100 & & & & & \\
\hline
\end{tabular}

Dari tabel hasil perhitungan kuesioner kita akan menghitung index\% untuk mengetahui nilai persentase dan masuk ke interval yang mana, untuk mengetahui nilai intervalnya kita akan mencari menggunakan persamaan (3).
Maka untuk penelitian kali ini $100 / 5=20$, Hasil (I) adalah 20, ini adalah intervalnya jarak dari terendah $0 \%$ hingga tertinggi $100 \%$ ). Berikut kriteria interpretasi skor berdasarkan interval ditunjukkan pada tabel 7 .

Tabel 7. Kriteria Interpretasi Skor nya Berdasarkan Interval

\begin{tabular}{|c|l|}
\hline Angka & \multicolumn{1}{|c|}{ Keterangan } \\
\hline $0 \%-19,99 \%$ & Sangat Tidak Setuju \\
\hline $20 \%-39,99 \%$ & Tidak Setuju \\
\hline $40 \%-59,99 \%$ & Cukup Setuju \\
\hline $60 \%-79,99 \%$ & Setuju \\
\hline $80 \%-100 \%$ & Sangat Setuju \\
\hline
\end{tabular}

Kemudian menjumlahkan nilai jawaban dimana pada tabel didapat jumlah jawaban sangat setuju dengan skor 5 adalah 50, jumlah jawaban setuju dengan skor 4 adalah 44 , jumlah jawaban cukup setuju dengan skor 3 adalah 6 , jumlah jawaban tidak setuju dengan skor 2 adalah 0 , jumlah jawaban sangat tidak setuju dengan skor 1 adalah 0 . Dengan menggunakan persamaan (2) didapat nilai sebagai berikut:

1. Jumlah jawaban sangat setuju (skor 5) adalah $50 \times 5=250$,

2. Jumlah jawaban setuju (skor 4 ) adalah $44 \times 4=176$,

3. Jumlah jawaban cukup setuju $=6 \times 3=18$,

4. Jumlah jawaban tidak setuju $=0 \times 2=0$,

5. Jumlah jawaban sangat tidak setuju $=0 \times 1=0$, Semua hasil dijumlahkan, total skor $=444$.

Dengan diketahui total skor adalah 444, maka dapat dihitung persentase menggunakan persamaan (1), dengan hasil perhitungan $444 / 500 \times 100==89 \%$. Nilai $89 \%$ berada pada interval $80 \%-100 \%$ yaitu Sangat Setuju.

\section{KESIMPULAN}

Dengan dibuatnya sistem SMS Gateway berbasis web dengan menggunakan modem GSM dapat mempermudah mahasiswa dalam mendapatkan informasi yang di inginkan, dan penyampaian informasi akademik kepada mahasiswa dan informasi pendaftaran kepada calon mahasiswa akan menjadi semakin mudah dan cepat, sistem SMS Gateway ini memiliki banyak fasilitas yang dapat digunakan sebagai penghubung antara pihak kampus dan mahasiswa dalam menyampaikan informasi.

Uji coba terhadap sistem yang dibuat hasilnya sesuai dan sistem dapat mengirim dan menerima pesan sehingga sistem dapat digunakan sesuai dengan perencanaan dan sistem dapat diimplementasikan di kampus STMIK Mahakarya.

Uji coba user terhadap sistem yang dilakukan menggunakan skala likert menghasilkan nilai persentase 89\% dimana nilai tersebut masuk kedalam interval kelima dengan pernyataan sangat setuju. 


\section{SARAN}

Penelitian ini masih perlu dikembangkan dengan menghubungkan sistem lainnya yang dibuat kampus, kemudian mengoptimalkan sistem keamanan dengan membatasi penggunaan maksimal dalam jangka waktu tertentu. Ke depannya penelitian bisa dibuat untuk menambahkan lebih banyak tools untuk mempermudah penggunaan sistem SMS Gateway dan mengembangkan dengan tidak hanya menggunakan web server sehingga sistem dapat digunakan dimana saja dengan pc atau laptop yang berbeda, dan pada penelitian selanjutnya dapat dilakukan pengembangan dengan memanfaatkan aplikasi whatsapp sebagai media pemberian informasi.

\section{DAFTAR PUSTAKA}

Briandana, R., Lestari, T. and Marta, R. F. (2020) 'Efektivitas Iklan Melalui SMS Blast Terhadap Keputusan Pembelian Konsumen', JURNAL LENSA MUTIARA KOMUNIKASI, 4(2), pp. 98112.

Dhini, V. A. (2021) Jumlah Pelanggan Telepon Seluler di Indonesia Meningkat pada 2020. Available at: https://databoks.katadata.co.id/datapublish/2021/10/ 06/jumlah-pelanggan-telepon-seluler-di-indonesiameningkat-pada-2020.

Dini, B. A. and Agmawarnida, A. (2018) 'Implementasi Waterfall Method Pada Aplikasi Penerimaan Peserta Didik Baru Berbasis Web Dengan Dukungan SMS Gateway Di SMPIT Insan Kamil', Jurnal Informatika SIMANTIK, 3(2), pp. 36-42.

Latukolan, M. L. A., Arwan, A. and Ananta, M. T. (2019) 'Pengembangan Sistem Pemetaan Otomatis Entity Relationship Diagram Ke Dalam Database', Jurnal Pengembangan Teknologi Informasi dan Ilти Koтputer e-ISSN, 2548, p. 964X.

Masruri, M. H. and Creativity, J. (2015) Membangun SMS Gateway dengan Gammu \& Kalkun. Elex Media Komputindo.
Pineng, M. (2017) 'Analisa Performansi Pengiriman Short Message Service (SMS) Pada Jaringan CDMA', Journal Dynamic Saint, 3(1), pp. 405416.

Sabharwal, S., Kaur, P. and Sibal, R. (2017) 'Empirical and Theoretical Validation of a Use Case Diagram Complexity Metric', International Journal of Information Technology and Computer Science, 9(11), pp. 35-47.

Shodikun, A. and Syam, E. (2018) 'Pembangunan sms gateway hasil pemeriksaan ujian sekolah berbasis web pada ma bahrul ulum singingi', Jurnal Teknologi Dan Open Source, 1(2), pp. 1-12.

Suendri, S. (2019) 'Implementasi Diagram UML (Unified Modelling Language) Pada Perancangan Sistem Informasi Remunerasi Dosen Dengan Database Oracle (Studi Kasus: UIN Sumatera Utara Medan)', Algoritma: Jurnal Ilmu Komputer Dan Informatika, 2(2), p. 1.

Supriatna, R. (2019) 'Implementasi Dan User Acceptance Test (UAT) Terhadap Aplikasi ELearning pada Madrasah Aliyah Negeri (MAN) 3 Kota Banda Aceh'. UIN Ar-Raniry Banda Aceh.

Supriyono, S. (2020) 'Software Testing with the approach of Blackbox Testing on the Academic Information System', IJISTECH (International Journal of Information System \& Technology), 3(2), pp. 227-233.

Tantowi, A., Pasha, D. and Priandika, A. T. (2021) 'Implementasi Sistem Informasi Pembauaran Berbasis SMS Gateway (Studi Kasus: SMK NEGERI 1 Bandar Lampung)', Jurnal Informatika Dan Rekayasa Perangkat Lunak, 2(2), pp. 188-195.

Utari, H. and Triana, Y. S. (2019) 'Sistem Informasi Monitoring Siswa Menggunakan SMS Gateway', Jurnal RESTI (Rekayasa Sistem dan Teknologi Informasi), 3(3), pp. 328-335. 